\title{
Article \\ Study on Antifatigue Crack Growth Characteristics of Ball-End Milling Bionic Surface
}

\author{
Youzheng Cui ${ }^{1,2, *}$, Fengjuan Wang ${ }^{1}$, Qingming $\mathrm{Hu}^{1,2,3}$ and Wei Zhang ${ }^{4}$ \\ 1 School of Mechanical and Electronic Engineering, Qiqihar University, Qiqihar 161006, China; \\ wfj320110@163.com (F.W.); huqingming1267@126.com (Q.H.) \\ 2 Heilongjiang Province Collaborative Innovation Center for Intelligent Manufacturing \\ Equipment Industrialization, Qiqihar 161006, China \\ 3 School of Mechatronics Engineering, Harbin Institute of Technology, Harbin 150001, China \\ 4 Key Laboratory of Advanced Manufacturing and Intelligent Technology, Ministry of Education, \\ Harbin University of Science and Technology, Harbin 150080, China; weizhanghust@yeah.net \\ * Correspondence: cuiyouzhenghust@163.com
}

Citation: Cui, Y.; Wang, F.; Hu, Q.; Zhang, W. Study on Antifatigue Crack Growth Characteristics of Ball-End Milling Bionic Surface. Coatings 2022, 12, 327. https:// doi.org/10.3390/coatings12030327

Academic Editor: Filippo Berto

Received: 22 January 2022

Accepted: 28 February 2022

Published: 1 March 2022

Publisher's Note: MDPI stays neutral with regard to jurisdictional claims in published maps and institutional affiliations.

Copyright: (C) 2022 by the authors. Licensee MDPI, Basel, Switzerland. This article is an open access article distributed under the terms and conditions of the Creative Commons Attribution (CC BY) license (https:// creativecommons.org/licenses/by/ $4.0 /)$.

\begin{abstract}
The surface morphology of parts has an important influence on service performance, such as wear resistance, fatigue resistance, and corrosion resistance. For example, the fatigue fracture resistance of the surface of the automobile cover mold directly determines the quality of the workpiece and the service life of the mold. In nature, the pit-shaped non-smooth form of the surface of certain organisms has good fatigue resistance. Using laser processing and other methods to prepare a pit-shaped bionic non-smooth surface on the surface of the part is an effective method to improve the fatigue resistance of the mold surface. Ball-end milling can form a regularly distributed pit-like surface morphology, and has the advantages of high processing efficiency, wide operating range, and low production cost compared with those of laser processing and preparation technology. It provides a new processing method for efficient milling preparation of bionic surfaces. In this paper, the morphology of the quadrilateral pits on the surface of the dung beetle is used as the prototype of the bionic design, and the mechanism of the antifatigue crack propagation characteristics of the quadrilateral pits of the bionic dung beetle is revealed and analyzed. The fatigue crack growth has a good retarding effect. At the same time, through numerical simulation and experimental research on the fatigue crack growth characteristics of the surface of the bionic pit, the results show that the source of fatigue cracks often starts inside the surface of the processed bionic pit, and the surface of the quadrilateral pit on the surface of the bionic dung beetle has good antifatigue crack growth characteristics.
\end{abstract}

Keywords: ball-end milling; bionic surface; hardened steel mold; fatigue crack growth; numerical simulation

\section{Introduction}

Hardened steel is a common material used to make automobile panel molds. The processed surface formed by the high-speed milling of the hardened steel mold reflects the surface state of its final use, and the processed surface state directly affects the service life of the mold [1]. During the stamping and forming process of automobile covering parts, the mold is subjected to repeated compressive stress and friction, which can easily cause defects such as pitting, abrasion, and scratches on the mold surface. It is easy to cause fatigue cracking on the mold surface for a long time, which leads to the mold. It is invalidated and scrapped, causing great economic losses. Therefore, it is of great practical significance and urgency to improve the performance of the mold. Surface topography is the most important parameter index to describe the surface integrity of the cutting process, and it has an important influence on the fatigue resistance of parts [2]. Huang et al. [3] studied the effect of high-speed ball-end milling tool path on its fatigue resistance. Studies 
showed that it is feasible to improve the fatigue resistance of high-speed, ball-end milling surfaces by selecting a suitable tool path. Suraratchai et al. [4] combined simulation and experiment, obtained the stress concentration factor of the two-dimensional surface topography through finite element simulation, established a fatigue life prediction model based on the stress concentration factor, and found that fatigue cracks originated from surface intermetallic compounds in the bottom of the trench. Yao et al. [5] studied the effects of milling parameters on three-dimensional surface morphology, surface roughness, and fatigue life based on high-speed side milling die steel processing experiments and tensile fatigue tests. A mathematical model between cutting parameters and fatigue life is established. As the surface stress concentration factor increases, the fatigue life decreases sharply. At the same time, the accuracy of the Arola prediction model is verified by tensile tests. The results show that, based on the surface stress concentration factor, the average error between the established fatigue life model and the test results is $6.25 \%$, and the fatigue crack starts at the intersection of the machined surface of the specimen.

Introducing the bionic non-smooth surface theory and technology to the application of hot work molds to improve its fatigue resistance, scholars at home and abroad conducted a lot of related research. Kamat, $\mathrm{S}$ et al. [6] used laser quenching and hardening technology to process the imitation shell surface strip texture on the surface of the hot work die steel. The study found that the hardened area after laser treatment played a role in preventing crack propagation and improved the hot work die. Fatigue resistance of steel surface. Inspired by bionics, Ma et al. [7,8] proposed a discontinuous laser melting crack repair method to repair the thermal fatigue cracks of the brake disk, thereby prolonging the service life of the brake disc and increasing repair efficiency of brake disks. Keith et al. [9] studied the fatigue life of thermally induced cracks in $\mathrm{H} 13$ tool steel. According to the traditional immersion test concept, thermal fatigue cracks were generated by cyclic heating and cooling. A finite element model was established to solve the thermal load, and the results were correlated with the experimental measurement results. A temperature-based prediction criterion is proposed, which can be derived from the modified general slope equation and used to describe the thermal fatigue crack life. Liu Lijun et al. [10] used laser surface melting and surface filling technology coupled with bionics to strengthen the texture of the diecasting mold surface, and they also analyzed the thermal fatigue crack growth morphology under different treatment methods; the thermal fatigue resistance of the bionic sample was significantly improved by laser coupling. Zhang and Jia et al. [11,12] applied the bionic nonsmooth surface to the mold to improve its thermal fatigue resistance. Cong Dalong et al. [13,14] studied the thermal fatigue resistance changes of H13 steel under two treatments: laser alloying and laser melting. Meng Chao et al. [15] used laser cladding technology to obtain a non-smooth surface on the surface of annealed H13 steel samples and compared the fatigue properties of the samples. Tong $X$ and Daim J et al. $[16,17]$ laser-processed the non-smooth surface of the shell onto the surface of the die steel material sample. The test results confirmed that this method can effectively improve the fatigue resistance of the material. Yin Yan et al. [18] used laser wire-filled cladding technology to repair fatigue cracks in Cr12MoV molds. Meng et al. [19] integrated the bionic theory and laser technology and discussed the relationship between the mechanical properties and thermal fatigue behavior of materials treated by selective laser surface melting. Yang et al. [20] used the laser bionic coupling technology (LBCT) treatment and found that the thermal fatigue of the thermal processing mold was significantly improved, and the effect of preventing the initiation and propagation of cracks was significant. Zhi et al. [21] used laser remelting bionic technology to prepare a coupled bionic model combination to enhance the local fatigue resistance of the mold, and they also compared the number of fatigue cracks and wear loss weights of the coupled bionic model at different temperatures. The mechanism of the bionic coupling model was analyzed, and it was determined that the bionic surface with dense row structure has strong resistance to fatigue and wear. Yuan et al. [22] prepared a grid-like bionic non-smooth coupling unit body on the surface of the H13 steel hot forging 
die by using appropriate laser process parameters. Studies found that it clearly improves the surface hardness, wear resistance, and thermal fatigue of the mold.

Through the analysis of the research conclusions of the above literature, there are many studies on the relationship between the stress concentration factor and the fatigue life based on the two-dimensional surface roughness. At the same time, for the research on the antifatigue performance of the bionic nongloss surface prepared by the exciting processing technology, the research objects are mostly concentrated on the thermal fatigue performance of the hot work die steel. However, there are few reports on the fatigue resistance of specific milling surface morphology. However, the milling surface morphology will inevitably affect the fatigue resistance of the machined surface. Therefore, it is necessary to study the antifatigue crack growth performance of the milling surface. In this paper, the shape of the quadrilateral pit on the body surface of the dung beetle and the shape of the hexagonal pit on the desert pit viper are selected as the bionic design prototypes. The surfaces with different bionic pit morphology are processed by high-speed ball-head milling technology (as shown in Figure 1), and the influence law of different bionic pit morphology on its antifatigue crack propagation characteristics is explored, At the same time, this paper effectively combines the relevant theories of bionic non-smooth surface with high-speed machining technology, which is of great practical significance to improve the safe service performance and prolong the service life of parts.

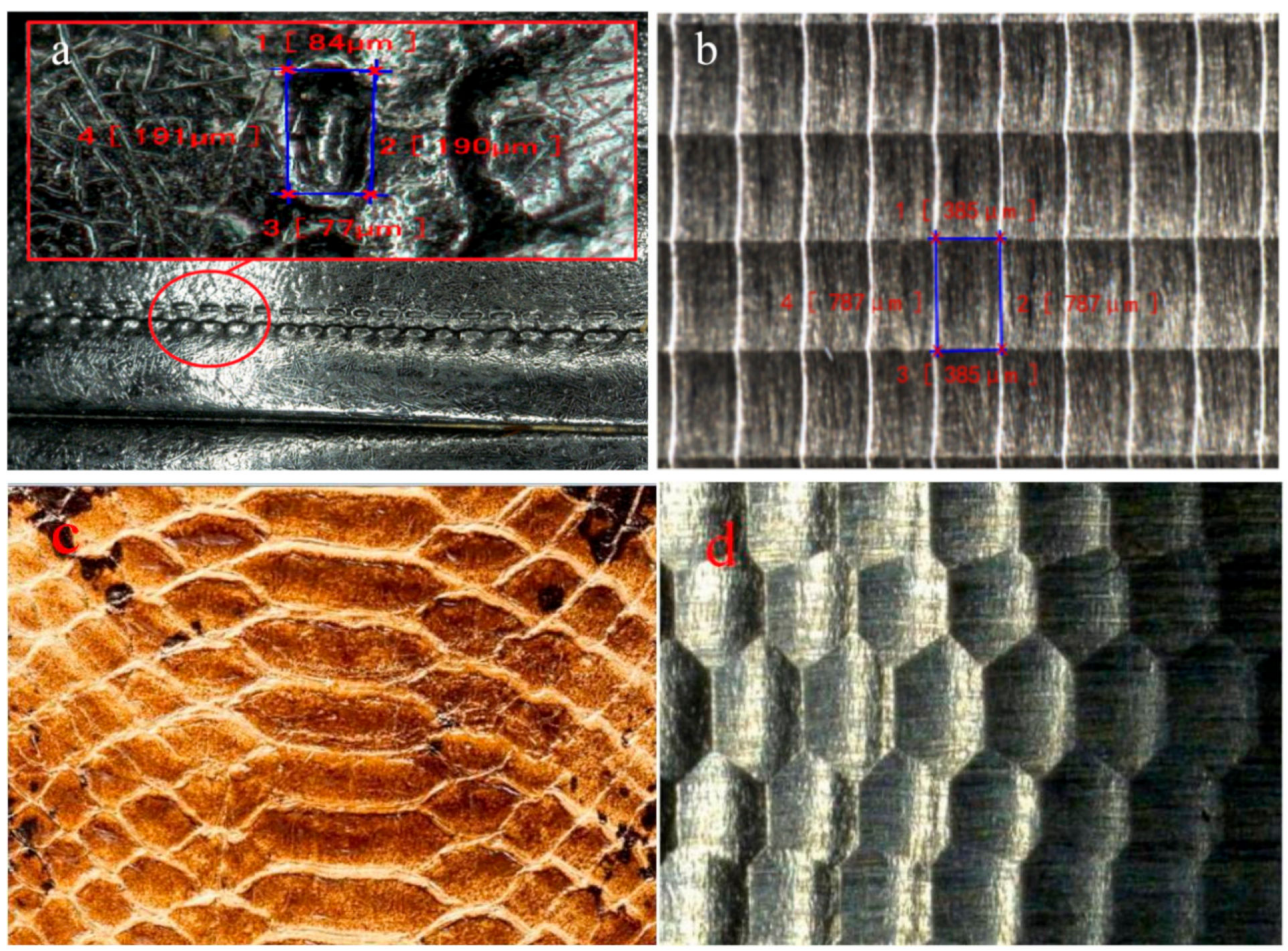

Figure 1. Different bionic design prototypes and milling process bionic non-smooth pit surface morphology. (a) Bionic design pattern of quadrilateral pits on surface of dung beetle; (b) quadrilateral bionic pits are obtained by ball-head milling; (c) hexagonal bionic design pattern on abdomen of desert belly snake; (d) hexagonal bionic pit morphology produced by ball-end milling.

\section{Materials and Methods}

\subsection{Theoretical Model of Fatigue Crack Growth Rate}

The linear elastic fracture mechanics method became the most commonly used method for fatigue crack growth analysis. In the linear elastic fracture mechanics theory, the stress intensity factor $K$ is commonly used to characterize the strength of the crack tip stress field, and its value depends on the size of the load, the shape of the crack, etc., [23]. In 1963, Paris et al. [24] first proposed to associate the fatigue crack growth rate with the stress 
intensity factor $\Delta K$. In this paper, the Paris formula widely used in engineering is used to describe the fatigue crack growth characteristics of the bionic specimen, and its expression. The formula is:

$$
\frac{d a}{d N}=C(\Delta K)^{m}
$$

In the formula, $a$ represents the crack length, $N$ represents the number of stress cycles, $d a / d N$ represents the crack growth rate, $C$ and $m$ are material constants, and $\Delta K$ represents the magnitude of the stress intensity factor.

$$
\Delta K=K_{\max }-K_{\min }=f \Delta \sigma \sqrt{\pi a}
$$

In the formula, $f$ represents the structural geometry and crack size coefficient, and $K_{\max }$ and $K_{\min }$ represent the maximum and minimum stress intensity factors, respectively; $\Delta K$ represents the stress amplitude at the crack.

\subsection{Materials and Tests}

This article selects hardened steel $\mathrm{Cr} 12 \mathrm{MoV}$ as the mold material. The microstructure of the sample section is observed under the scanning electron microscope (SEM, Thermo Fisher Scientific, Waltham, MA, USA), as shown in Figure 2. From the figure, it is observed that the matrix material of hardened steel $\mathrm{Cr} 12 \mathrm{MoV}$ is uniformly distributed with needle martensite, a small amount of carbide, and a small amount of residual austenite. The chemical composition of the material is shown in Table 1, and the physical properties of the material are shown in Table 2. The fatigue life of bionic fatigue specimens was tested by Instron 8801 at room temperature. The loading mode of fatigue test is the alternating cyclic fatigue of the axial tension. In this paper, the larger tensile load is $23.1 \mathrm{kN}(80 \%$ of the average ultimate tensile load), the selected frequency is $15 \mathrm{~Hz}$, the stress ratio is $\mathrm{r}=0.1$, the waveform is sinusoidal, and the load spectrum is shown in Figure 3. The fatigue test site and clamping method are shown in Figure 4.

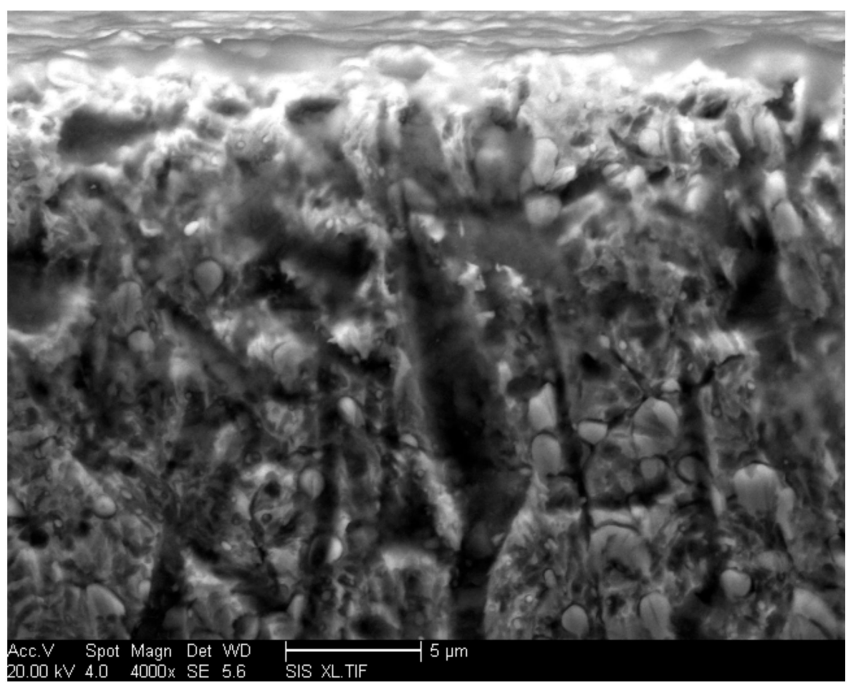

Figure 2. Microstructure of hardened steel Cr12MoV.

Table 1. Chemical composition of Cr12MoV hardened steel [25].

\begin{tabular}{cccccc}
\hline Element & $\mathbf{C}$ & $\mathbf{C r}$ & Mo & V & Mn \\
\hline Content & $1.45-1.47$ & $11-12.5$ & $0.4-0.6$ & $\leq 0.3$ & $\leq 0.4$ \\
\hline Element & $\mathbf{S i}$ & $\mathbf{N i}$ & $\mathbf{C u}$ & $\mathbf{S}$ & $\mathbf{P}$ \\
\hline Content & $\leq 0.4$ & $\leq 0.25$ & $\leq 0.3$ & $\leq 0.03$ & $\leq 0.03$ \\
\hline
\end{tabular}


Table 2. Physical characteristics of Cr12MoV hardened steel [26].

\begin{tabular}{|c|c|c|c|c|}
\hline Elastic Modulus E (GPa) & Poisson's Ratio $v$ & Density $\left(\mathrm{kg} / \mathrm{m}^{3}\right)$ & Yield Strength (MPa) & Tensile Strength (MPa) \\
\hline 180 & 0.30 & 7750 & 610 & 850 \\
\hline
\end{tabular}

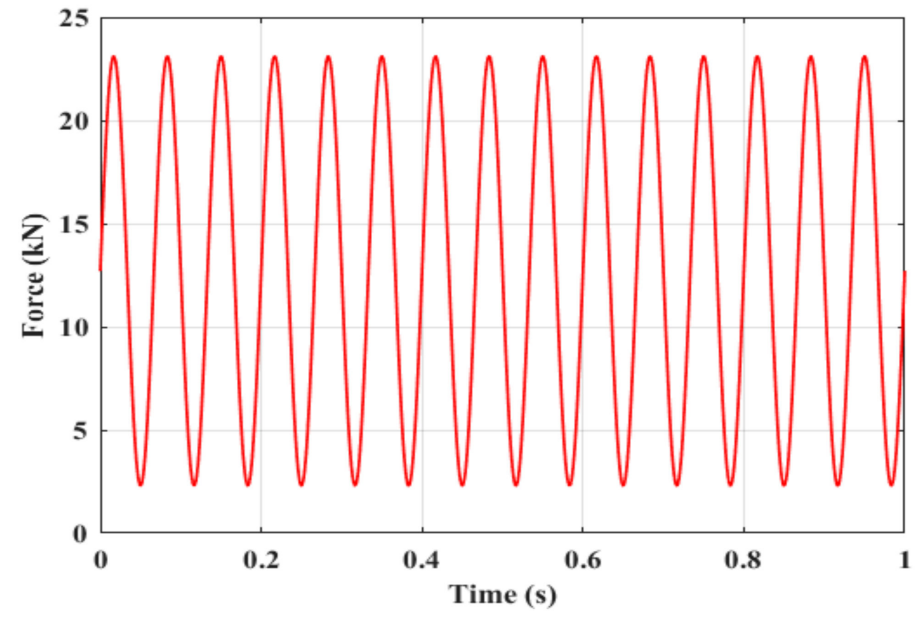

Figure 3. Fatigue test load spectrum.

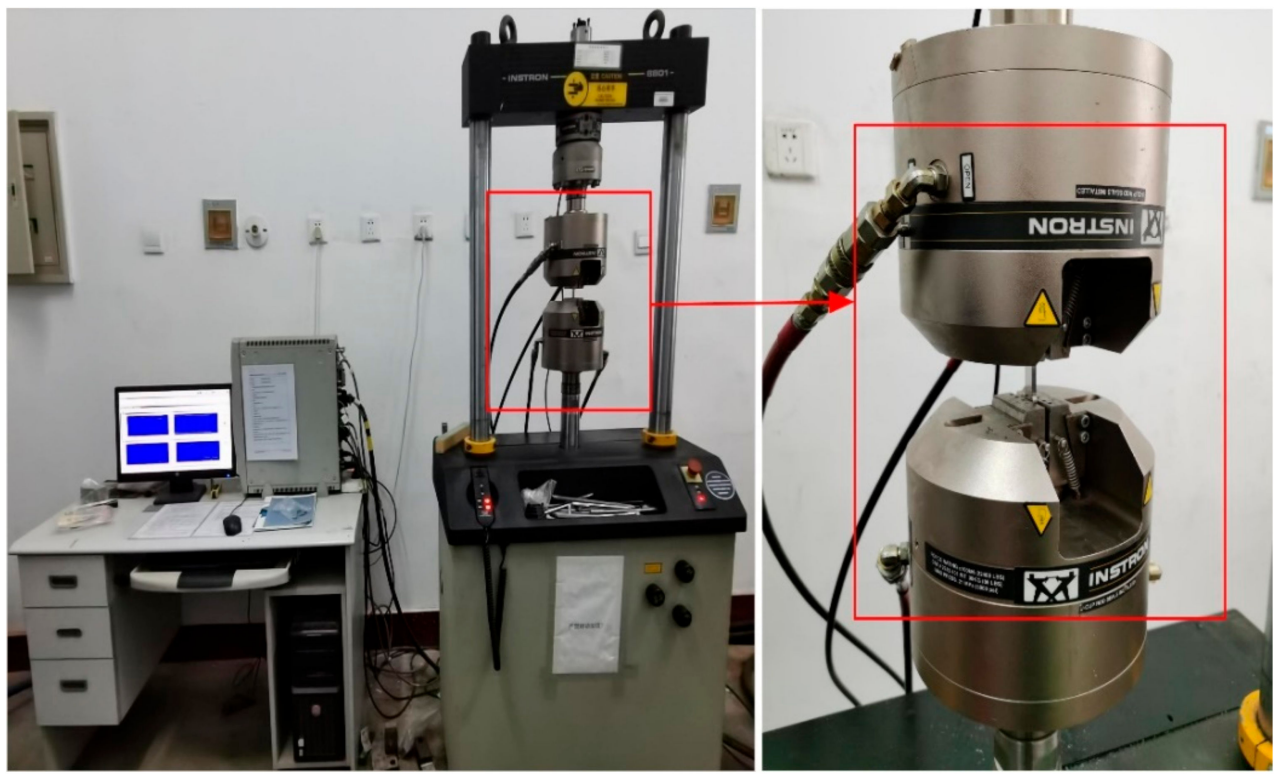

Figure 4. Fatigue test site.

\subsection{Shape Modeling and Simulation}

The morphology of quadrilateral pits on the surface of dung beetle was measured by ultra-depth of field electron microscope VHX-100(KEYENCE, Osaka, Japan). Combined with relevant literature [27], the depth of pits was about 10-20 $\mu \mathrm{m}$, the length is 100-200 $\mu \mathrm{m}$, and the width is 70-100 $\mu \mathrm{m}$. At the same time, with the help of Taylor Hobson CCIMP white light interferometer (Taylor Hobson, Lester, Britain) produced in Britain, the bionic test piece with quadrilateral pits milled by the ball head is microscopically observed. The observation results are shown in Figure 5, in which the depth of the morphology of the quadrilateral pits of the bionic test piece is $19.95 \mu \mathrm{m}$. The size range of other pits is also consistent with the shape and size of quadrilateral pits on the surface of dung beetle. To make the pits on the surface of the model closer to the surface shape of the actual ball head after milling, in this paper we use the three-dimensional modeling software UG (12.0, 
SIEMENS AG, Munich, Germany) to parameterize the three bionic pit morphologies of quadrilateral, hexagonal, and irregular disordered pits. Among them, because the surface morphology of ball-head milling is affected by the actual machining conditions such as cutting parameters, machine tool vibration, and tool wear, irregular and disordered pits will be randomly formed on the machined surface. To truly predict and numerically simulate the fatigue life value of the bionic fatigue specimen, the three-dimensional modeling of the bionic fatigue specimen will be drawn in strict accordance with the size of the actual bionic fatigue specimen. The modeling parameters correspond to the cutting parameters, in which the feed rate of each tooth is $f_{\mathrm{z}}=0.4 \mathrm{~mm}$, the feed rate of row spacing is $a_{\mathrm{e}}=0.8 \mathrm{~mm}$, the cutting depth is $a_{\mathrm{p}}=0.3 \mathrm{~mm}$, and the radius of ball-end milling cutter is $R=10 \mathrm{~mm}$. The three-dimensional model of the bionic fatigue specimen is drawn, as shown in Figure 6 . At the same time, based on the XFEM function in ABAQUS (2018, Dassault, Providence, RI, USA), the fatigue crack propagation process of different bionic pit surface fatigue specimens is simulated and analyzed in this paper.

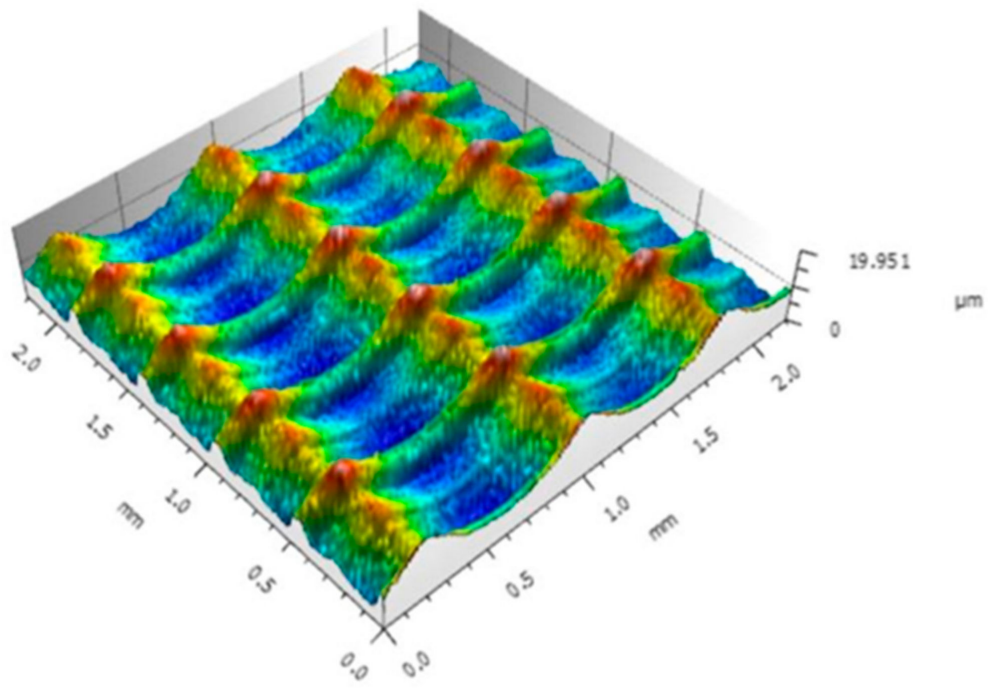

Figure 5. Observation results of surface morphology of quadrilateral pits.

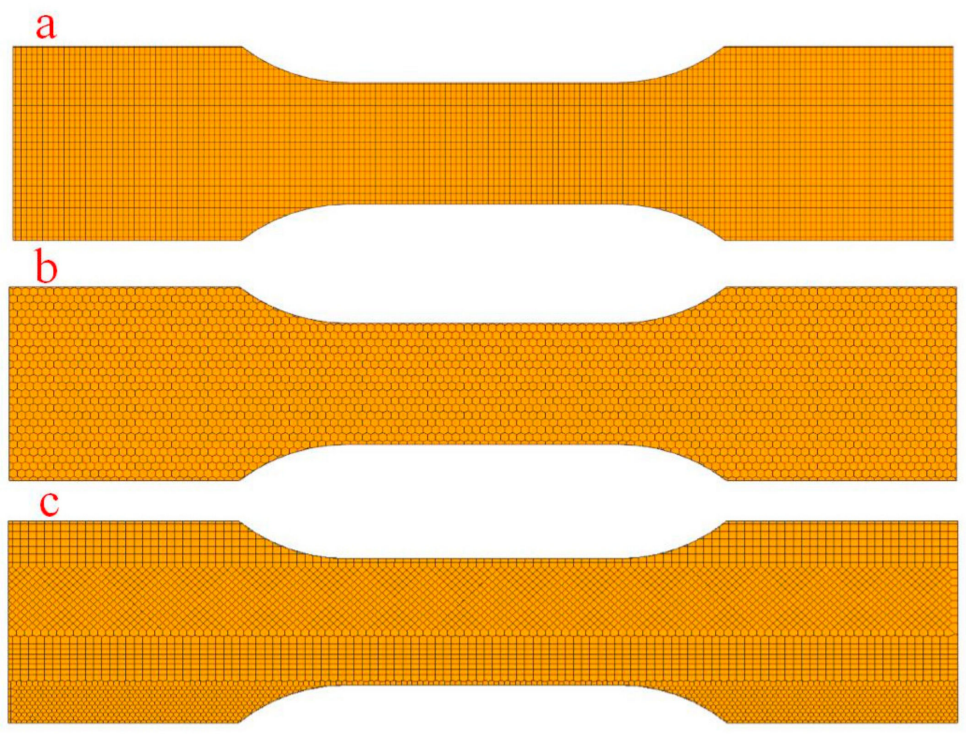

Figure 6. Three-dimensional models of different bionic fatigue specimens: (a) quadrilateral bionic pit fatigue specimen; (b) hexagonal bionic pit fatigue specimen; (c) irregular and disorderly pit fatigue specimen. 


\section{Analysis of Antifatigue Crack Growth Mechanism of Bionic Pit-Shaped Surface}

In this paper, the antifatigue crack propagation mechanism of the bionic specimen is analyzed by referring to the non-smooth morphology of the quadrilateral pits on the body surface of the dung beetle. Through the analysis of the schematic diagram of the single edge arresting crack growth model of the quadrilateral pit unit in Figure 7, it is clear that when a single quadrilateral edge appears at the front of the crack, the crack growth is blocked. As the fatigue effect continues, the fatigue crack cannot break through quickly. In the edge unit body, the main crack has to be bridged with other microcracks distributed on both sides. Macroscopically, the crack was deflected, but the crack cannot bypass the edge randomly and can only continue to grow in a new direction; the damage is further intensified. When the crack tip encounters the weaker edge, the edge unit body will gradually be torn, and the edge unit will continue to grow along the original direction through the edge, which makes the fatigue crack propagation path longer and consume more. More energy required for fatigue crack growth slows down the rate of fatigue crack growth and has a good inhibitory effect on fatigue crack growth.

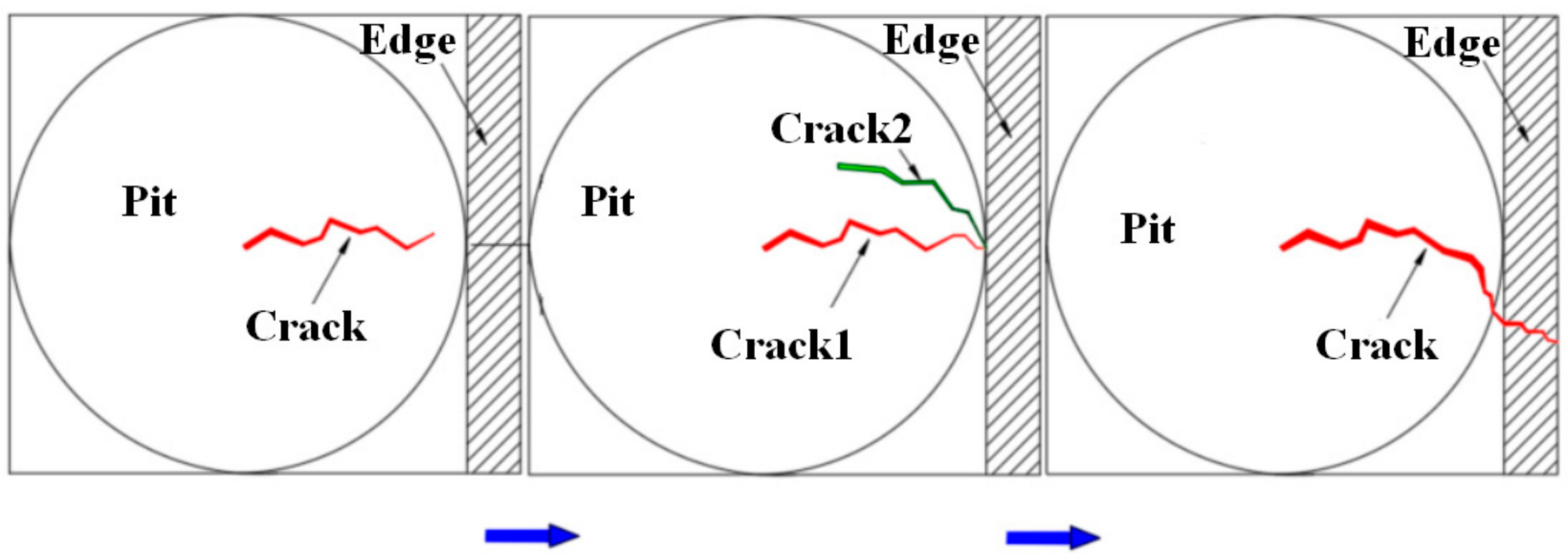

Figure 7. Schematic diagram of a single edge retarding crack propagation model of a quadrilateral pit element.

It was necessary to verify that the surface morphology of the quadrilateral bionic pits has a better retarding effect on fatigue crack growth; therefore, the fatigue tensile test of the polished surface fatigue specimen and the quadrilateral bionic pit surface morphology fatigue specimen was designed. Figure 8 is a comparison diagram of the fatigue tensile fracture test of the polished surface fatigue specimen and the quadrilateral bionic pit morphology fatigue specimen. Through the observation and analysis of the fatigue fracture morphology of the polished surface fatigue specimen in Figure 8a, the polished surface evidently has no bionic pits. The edge of the pit surface inhibits the growth of fatigue cracks, and the macroscopic morphology of the fatigue fracture is basically a linear fracture. Then, through the observation and analysis of the fatigue fracture of the surface morphology of the quadrilateral bionic pit in Figure $8 \mathrm{~b}$, the fatigue crack growth direction is constantly increasing due to the retardation effect of the four edges of the quadrilateral bionic pit on the fatigue crack growth. Deflection occurs, resulting in the fatigue fracture macroscopic morphology of a longer arc-shaped fracture surface, and the path of fatigue crack growth is significantly longer, indicating that it consumes more energy in the process of fatigue crack growth and delays fatigue. The rate of crack growth has a good inhibitory effect on fatigue crack growth. The comparative test results show that the surface morphology of the quadrilateral bionic pits has good accuracy in the analysis of the mechanism of inhibiting fatigue crack growth. 

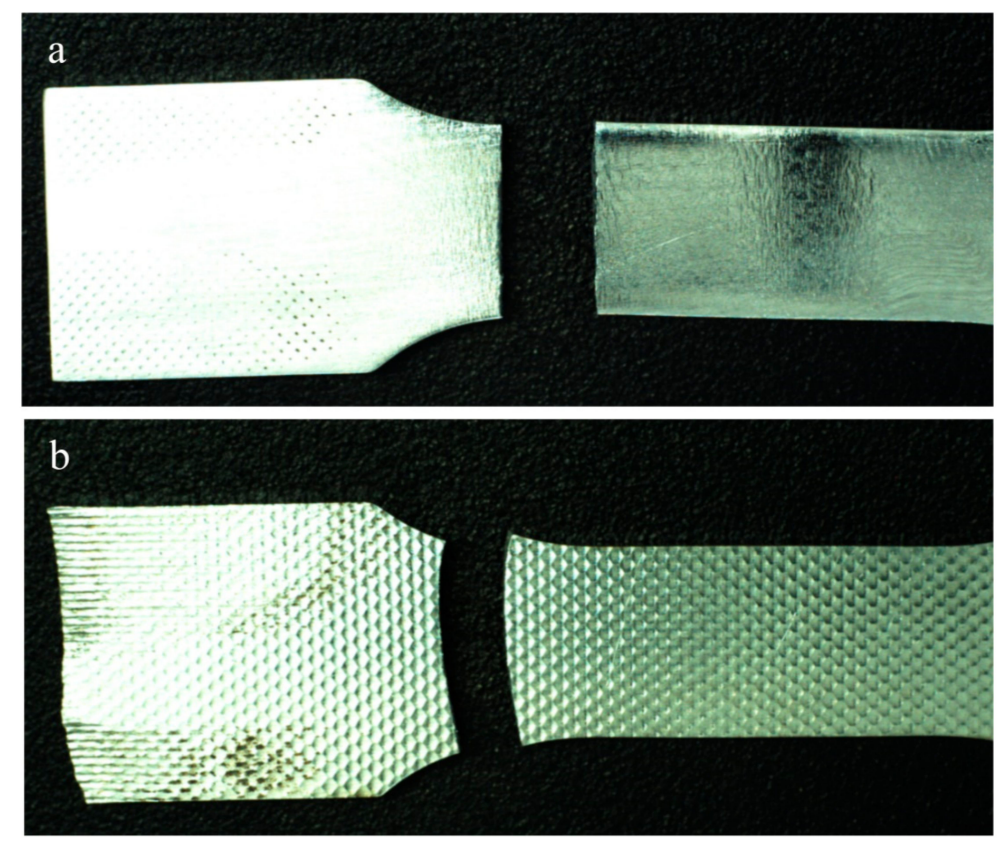

Figure 8. Comparison of fatigue tensile fracture of polished surface and surface morphology of quadrilateral bionic pit: (a) fatigue fracture of polished surface; (b) fatigue fracture of quadrilateral bionic pit surface.

\section{Fatigue Crack Growth Analysis of Different Bionic Pit Surface Topography}

\subsection{Analysis of Fatigue Crack Growth of Random Irregular and Disordered Dimples}

Figure 9 shows the comparison of the fatigue crack growth process of the fatigue specimen with random irregular pits and the test results. Figure 9a is the initiation stage of the crack propagation of the fatigue specimen model with random irregular pits. An initial crack sprouted on the surface of the lower-left corner of the middle section of the specimen. Due to the morphology of the bionic pits, there is a stress concentration phenomenon on the surface. The intersection of the arc and the middle straight line is a typical stress concentration location where fatigue cracks are initiated. As the fatigue crack continues to expand (as shown in Figure 9b) until it reaches the overall transverse fracture of the test piece, due to the blocking of the pit edges, its fracture is a moderately arc-shaped linear fracture crack (as shown in Figure 9c). Figure $9 d$ shows the test results of the fatigue specimen with random and irregular pits. By comparing the simulation results of the fatigue crack of the specimen model with the test results, the shape of the fatigue crack is consistent.

\subsection{Analysis of Fatigue Crack Growth of Hexagonal Bionic Pits}

Figure 10 shows the comparison of the fatigue crack growth process of the hexagonal bionic pit shape fatigue specimen with the test results. Figure 10a shows the initiation stage of the crack growth of the fatigue specimen model of the hexagonal bionic pit shape. Due to the existence of the bionic pit shape, the initial crack initiation position and the initial stage of the random irregular chaotic pit shape specimen are affected. The crack initiation position is similar. With the continuous application of the fatigue tensile load, the fatigue crack growth stage (as shown in Figure 10b) increases until it extends to the overall transverse fracture of the specimen (as shown in Figure 10c). Figure 10c shows that the curvature of the arc-shaped straight line of the fatigue crack of the specimen is smaller than that of the specimen with random irregular pits, and the path in the fatigue crack propagation process is relatively longer, which consumes energy. It is also relatively increased, delaying the rate of fatigue crack initiation and growth, which indicates that the fatigue resistance of the hexagonal bionic pit morphology is better than that of the random and irregular pit morphology. In addition, by comparing the simulation results 
of the fatigue crack fracture of the specimen with the test results, the shape of the fatigue crack is also relatively consistent.

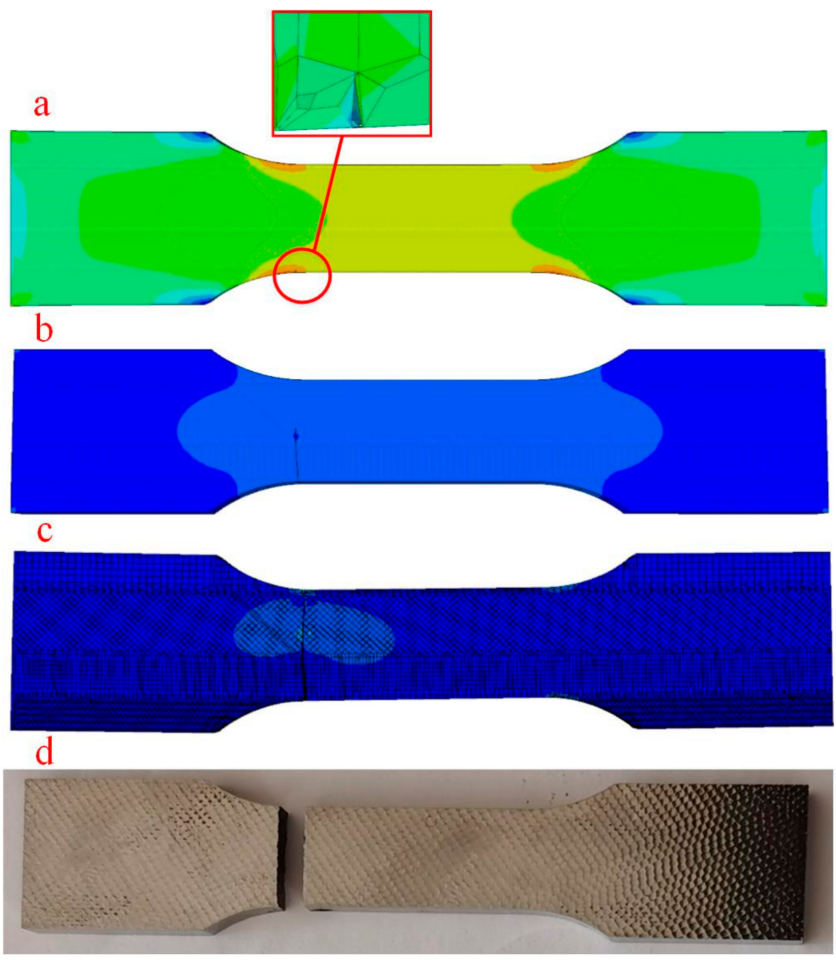

Figure 9. Comparison of fatigue crack growth process of fatigue specimen model with random irregular disorder pits and test results: (a) initial crack initiation; (b) crack growth; (c) fatigue fracture; (d) fatigue fracture test results.
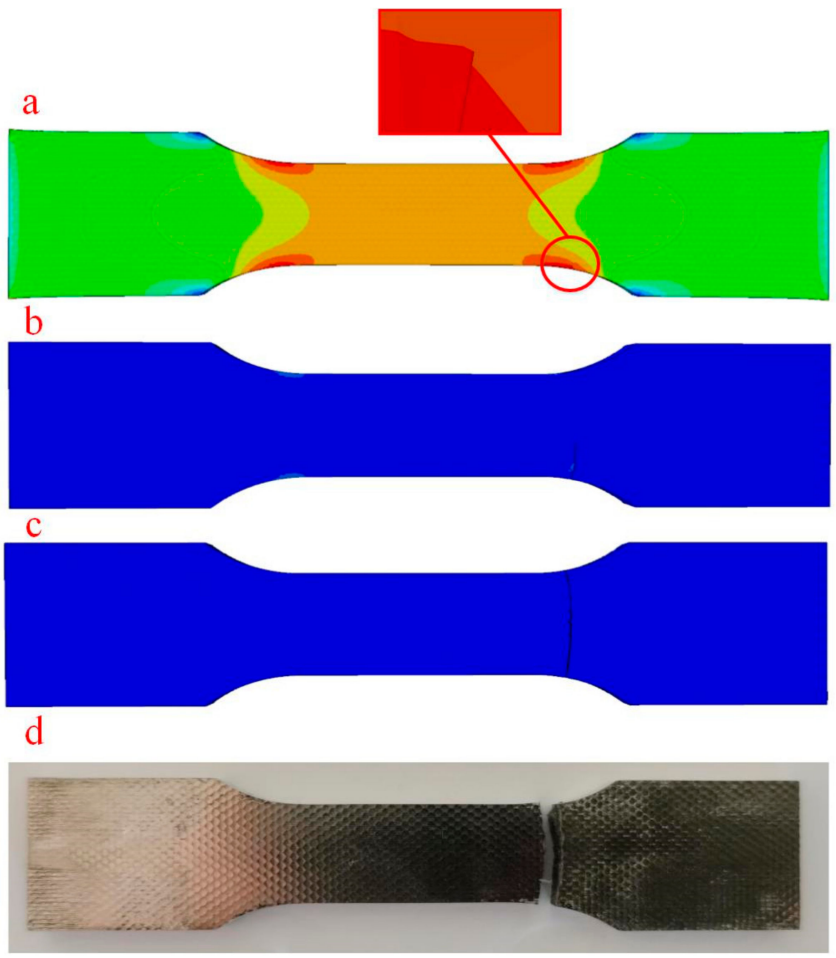

Figure 10. Comparison of fatigue crack growth process of fatigue specimen model with hexagonal bionic pit shape and test results: (a) initial crack initiation; (b) crack growth; (c) fatigue fracture; (d) fatigue fracture test results. 


\subsection{Analysis of Fatigue Crack Growth of Quadrilateral Bionic Pits}

Figure 11 shows the comparison of the fatigue crack growth process of the quadrilateral bionic pit shape fatigue specimen with the test results. Figure 11a shows the initiation stage of the crack propagation of the quadrilateral bionic pit morphology fatigue specimen model. Due to the existence of the bionic pit morphology, the initial crack initiation position and the initial crack initiation of the hexagonal bionic pit morphology specimen are affected, and the location is similar. At the same time, with the continuous application of the fatigue tensile load, the fatigue crack growth stage (as shown in Figure 11b) increases until the overall transverse fracture of the specimen (as shown in Figure 11c) occurs. However, Figure 11c shows that the curvature of the arc-shaped straight line of the fatigue crack of the quadrilateral bionic pit profile specimen is the minimum of the three schemes, which means that the fatigue crack propagation path is the longest. The reason for this phenomenon is that the single edge of the quadrilateral prevents the crack propagation. As the fatigue effect continues, the fatigue crack cannot break through the front edge in a short time, and the main crack has to occur with other microcracks distributed on both sides. Bridging, macroscopically, the crack was deflected, and the extension of the propagation path causes more energy to be consumed during the crack propagation process, inhibiting the growth rate of fatigue cracks and improving its fatigue resistance. By comparing the fatigue fracture test results of the quadrilateral bionic pit shape in Figure 11d with the fatigue fracture simulation results, the fatigue crack shape is consistent, and the simulation and test are combined to verify the previous simulation of the dung beetle body surface. The morphology of the quadrilateral bionic pits has a good antifatigue performance, and the correctness of the mechanism analysis also further shows that the morphology of the quadrilateral bionic pits on the surface of the dung beetle has good fatigue resistance.

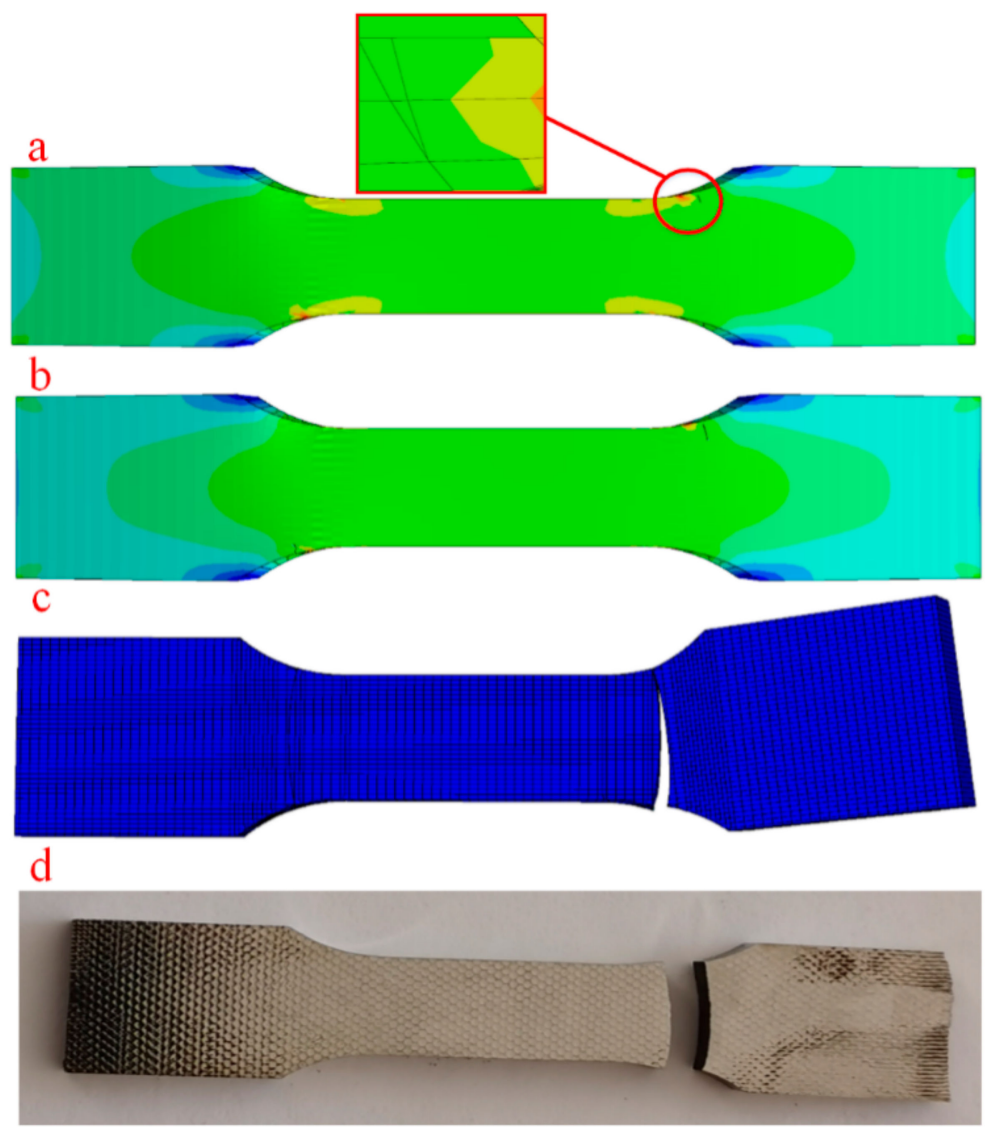

Figure 11. Comparison of fatigue crack growth process of quadrilateral bionic pit shape fatigue specimen model and test results: (a) initial crack initiation; (b) crack growth; (c) fatigue fracture; (d) fatigue fracture test results. 


\subsection{Microstructure Analysis of Subsurface and Machined Surfaces of Fatigue Specimens}

Mold fatigue is the result of the comprehensive action of many factors, such as the machining surface quality of parts and the essence of materials, among which the essence of materials mostly refers to microstructure and internal defects. The existing research results also show that high-strength alloy steel materials have obvious sensitivity to fatigue strength and stress concentration. More than $80 \%$ of fatigue cracks in fatigue failure of high-strength alloy steel components start from defects such as machining knife marks, scratches, or inclusions [28]. The surface quality and material essence of the die obtained by milling jointly determine the service performance and fatigue life of the parts. The stress concentration caused by cutting and the defects of the die itself affect the fatigue life of the die. The observation and analysis of the subsurface microstructure of the bionic pit fatigue specimen in Figure 12a show that there are microcracks, micropores, and other defects on the subsurface of the fatigue specimen. Combined with the machining tool marks and scratches on the machined surface through high-speed milling and the microcracks and micropores at the bottom of the pit (as shown in Figure 12b), the fatigue life of the die is affected. Fatigue cracks cause microdefects on the surface of the die. The stress at the microdefects is complex, which easily causes stress concentration. If the stress is large and exceeds the bearing capacity of the die, macrocracks that affect the service life of the die are formed. Therefore, hardened steel die has good material essence and better machined surface quality, which is helpful to improve its fatigue fracture resistance.

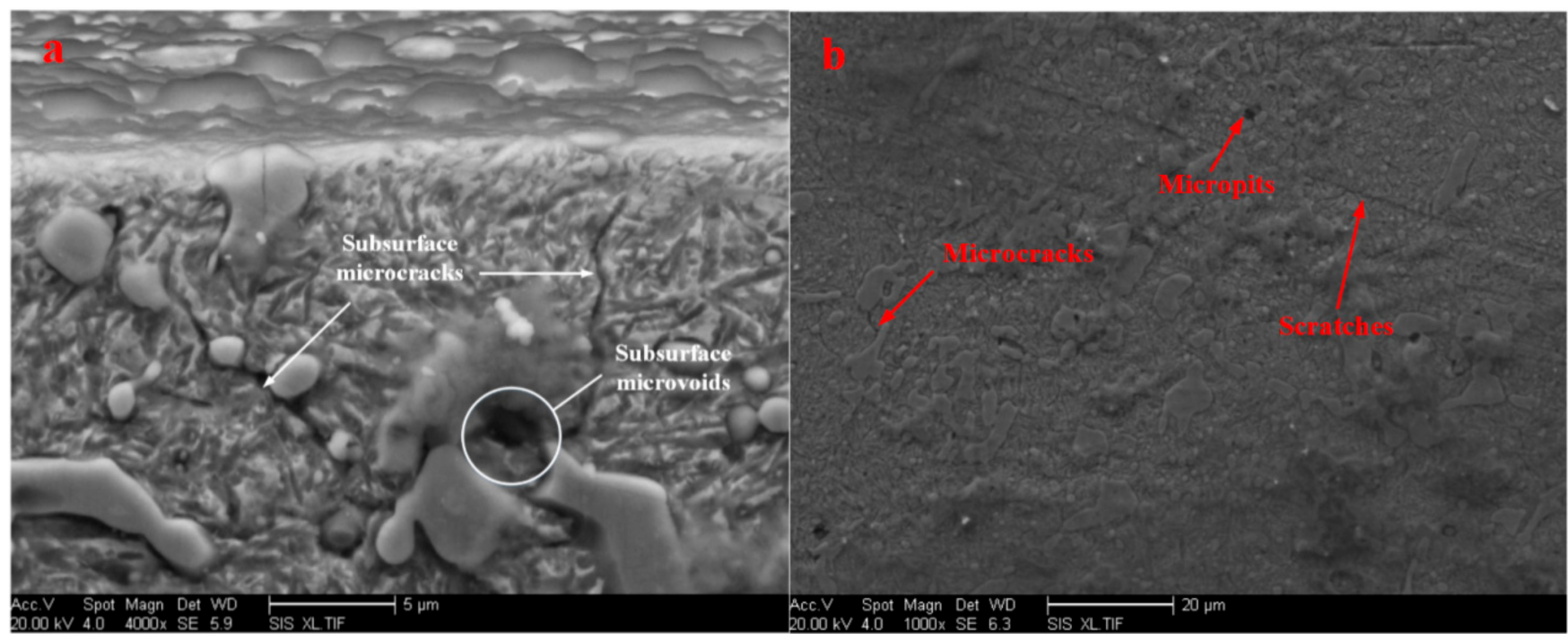

Figure 12. Microstructure of subsurface and machined surface of bionic pit fatigue specimen: (a) microstructure of subsurface layer of fatigue specimen; (b) microstructure of milled surface of fatigue specimen.

\subsection{Analysis of Fatigue Crack Growth of Quadrilateral Bionic Pits}

Through the macroscopic observation results of the fatigue fracture of the hexagonal bionic pit specimen in Figure 13a, the fracture is relatively neat from the overall view of the fracture morphology, and there is no obvious deformation. The type of fracture is brittle fracture in the macroscopic view. The selected high-carbon alloy steel $\mathrm{Cr} 12 \mathrm{MoV}$ contains high carbon content and is consistent with hardenability. At the same time, the Figure 13a shows that the initial crack source of fatigue cracks comes from the machined surface, indicating that there will be stress concentration through high-speed milling. Phenomenal or microprocessing defects are mostly the root cause of initial fatigue cracks, which confirms the correctness of the previous analysis. From the microscopic observation results of the fatigue fracture in Figure 13b, an obvious fatigue crack originated from the machined surface and extended longitudinally downward along the crack to the inside 
of the specimen. At the same time, a large number of cleavage steps can be seen from Figure 13c, and a certain fibrous dimples are found in the interior of the specimen from Figure 13d, indicating that significant plastic deformation also occurred here. According to Figure $13 c, d$, the microscopic form of the fatigue fracture is a mixed fracture form mainly composed of cleavage fracture and a small amount of dimple fracture. The tensile strength of the bionic fatigue specimen further enhances the fatigue resistance of the bionic surface.
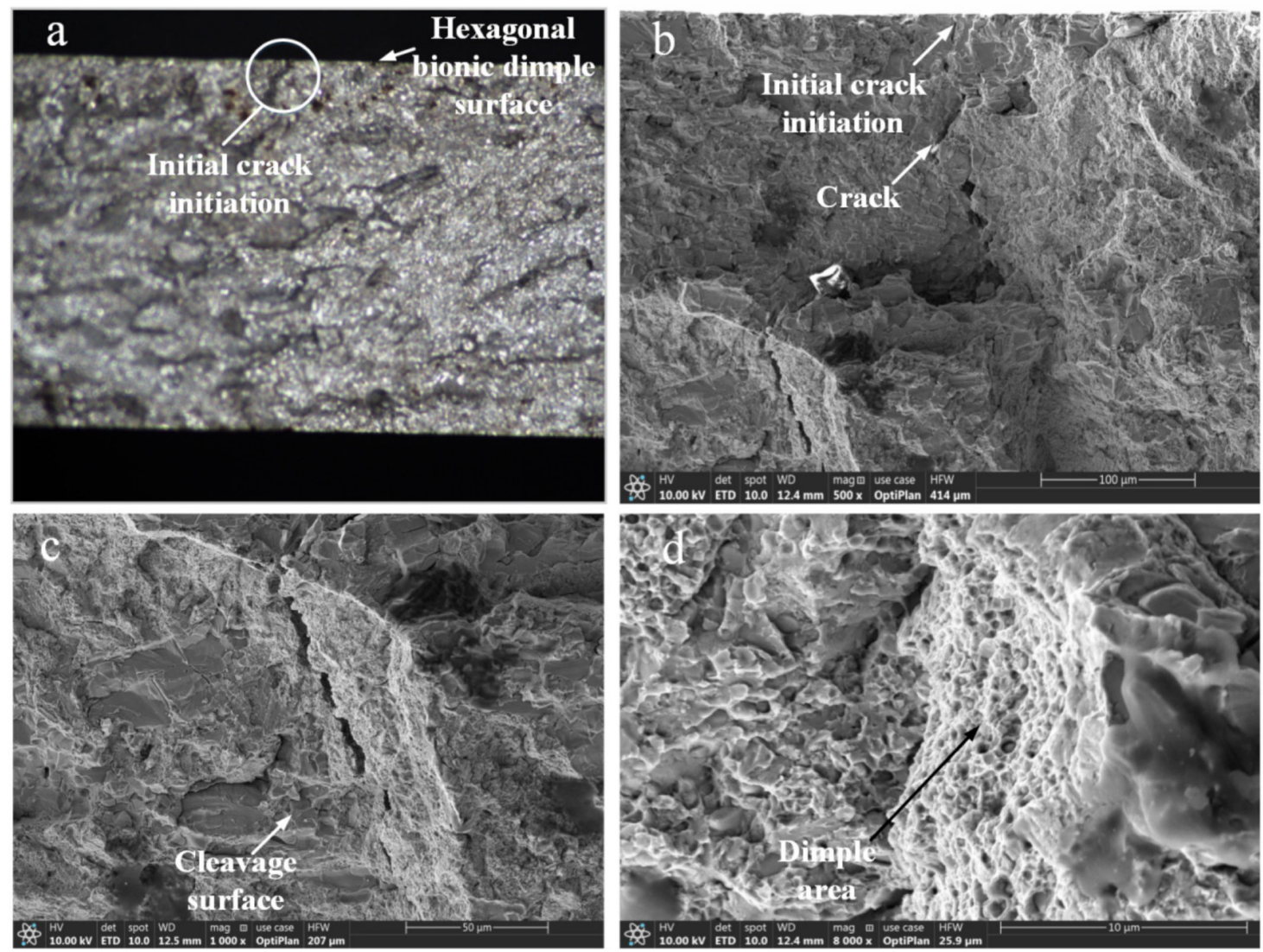

Figure 13. Observation results of macroscopic and microscopic characteristics of fatigue fracture of hexagonal bionic pit-shaped fatigue specimen: (a) macroscopic observation results of fatigue fracture of hexagonal bionic pit fatigue specimen; $(\mathbf{b}-\mathbf{d})$ observation on micro characteristics of fatigue fracture surface of hexagonal bionic pit fatigue specimen.

Figure 14 shows the microscopic observation results of the fatigue fracture of the quadrilateral bionic pit specimen. From Figure 14a, the initial source of fatigue cracks also starts on the machined surface, indicating that there will be stress concentration or microprocessing defects in high-speed milling, which are mostly triggered as the source of initial fatigue cracks. This further confirms the previous article and the correctness of the fatigue crack propagation analysis on the surface of the quadrilateral bionic pit. From the microscopic observation results of the fatigue fracture in Figure 14b, an obvious fatigue crack starts from the machined surface, and it also extends longitudinally downward along the inside of the specimen along this crack. At the same time, a large number of cleavage steps can be seen from Figure 14c, and certain fibrous dimples are found in the specimen from Figure 14d, indicating that significant plastic deformation also occurred here, indicating that the quadrilateral bionic dimple shape is affected. The fatigue fracture morphology and fracture form are similar to the fatigue fracture morphology and fracture form of the hexagonal bionic pit, and it is also a mixed fracture form with a mainly cleavage fracture and a small amount of dimple fracture. In addition, it also shows that there is a certain plastic deformation inside the material, which can improve the fatigue resistance of the bionic fatigue specimen to a certain extent. 

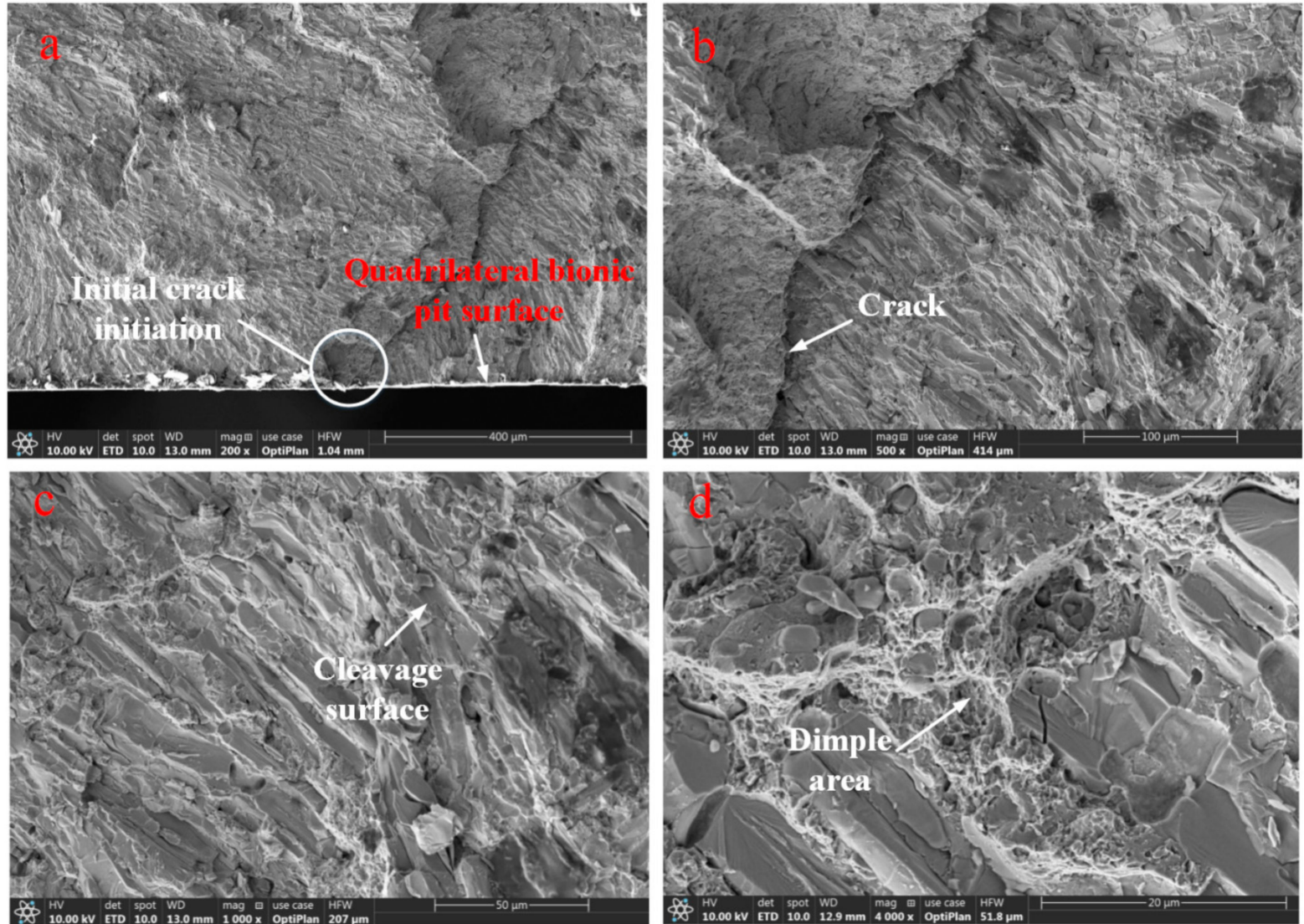

Figure 14. Observation results of microscopic characteristics of fatigue fracture of quadrilateral bionic pit morphology fatigue specimen: (a) observation results of macroscopic characteristics of fatigue fracture surface of quadrilateral bionic pit fatigue specimen; (b-d) observation on micro characteristics of fatigue fracture surface of quadrilateral bionic pit fatigue specimen.

\section{Comparative Analysis of Characteristic Parameters of Fatigue Crack Growth on Different Bionic Surfaces}

Based on the previous analysis results, the bionic quadrilateral pits on the surface of the dung beetle have better characteristics for retarding fatigue crack growth, which means that the bionic morphology has better fatigue resistance. In this paper, starting from the perspective of the change law of the fatigue crack growth characteristic parameters of the fatigue specimen models with different bionic pit shapes, the fatigue resistance performance of the fatigue specimen models with different bionic pit shapes is further analyzed.

From the analysis of the a-N curve of fatigue crack growth of different bionic profile models in Figure 15a, the crack growth rate curves of fatigue specimen models of different bionic profile models are basically consistent with the pairs' fatigue crack growth rates, showing a linear increasing trend. The figure also shows that the quadrilateral bionic pit morphology has good performance in retarding fatigue crack growth due to its closed and long-distance edge, and it is a fatigue specimen with three different bionic pit morphologies. The middle is the model with the slowest fatigue crack growth rate, which shows good resistance to fatigue crack growth. At the same time, in the fatigue specimen model of random irregular and disordered pit morphology, due to the uneven distribution of the surface morphology, the stress distribution and stress concentration are also unevenly distributed, resulting in the fastest fatigue crack growth rate. The morphology of the hexagonal bionic pits also has a certain edge to retard the fatigue crack growth, which also makes the fatigue crack growth rate relatively slow. The growth curve of stress intensity factor versus crack length in Figure 15b shows that as the length of the crack increases, 
the stress intensity factor of the random irregular chaotic pit model changes the fastest, and the stress field at the crack tip increases too fast. The crack is quickly destabilized and expanded. The change curve of the quadrilateral bionic pit morphology model is the gentlest. During the crack propagation, the stress field at the crack tip increases the slowest, and it increases sharply to a critical value in the final stage of crack propagation, which leads to the model's instability and fracture.

\section{a}

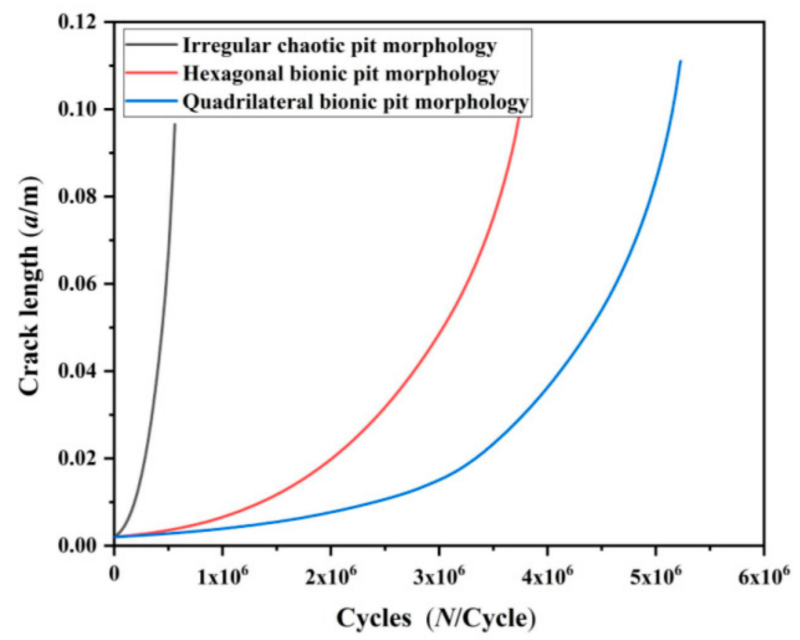

b

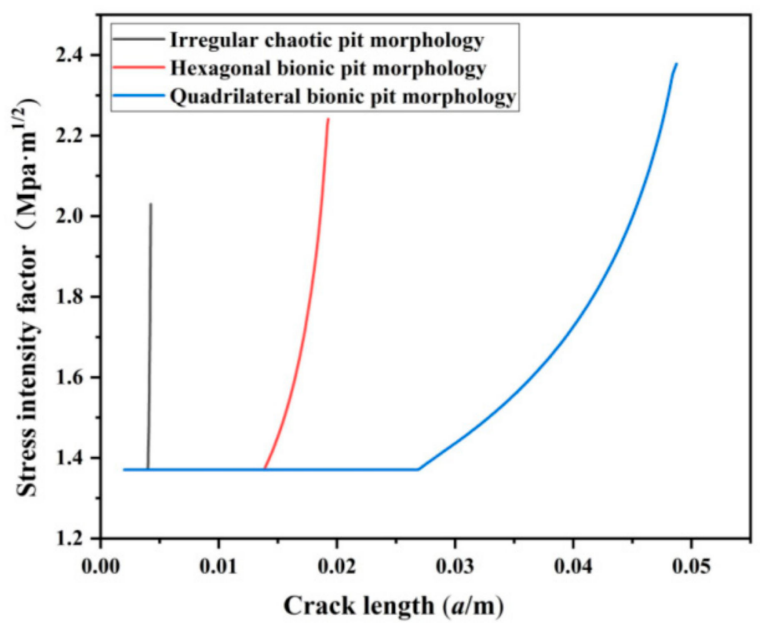

Figure 15. Comparison of fatigue crack growth characteristic parameters of different bionic pit morphology models: (a) fatigue crack growth $a-N$ curve of different bionic morphology models; (b) relationship curve between stress intensity factor and crack length.

In summary of the above comparative analysis, the quadrilateral bionic pit profile model has the smallest crack growth rate and stress intensity factor change rate under the same analysis conditions, showing good antifatigue crack growth characteristics.

\section{Conclusions}

In this paper, the antifatigue crack growth characteristics of the surface morphology of ball-end milling bionic pits are studied. Numerical simulation combined with fatigue tensile test is used. The fatigue fracture is also micrographed using ultra depth-of-field electron microscope and scanning electron microscope. Through observation and analysis, we obtained the following main conclusions:

(1) By comparing the morphology of quadrilateral pits on the surface of the imitated dung beetle, the hexagonal pits of the imitated desert viper, and the pits with random and irregular distribution, the fatigue fracture morphology and fatigue crack propagation characteristic parameters, among which was the surface of the imitated dung beetle, were superior in the morphology of quadrilateral pits, which also have good fatigue crack growth resistance;

(2) By revealing and analyzing the mechanism of fatigue crack growth retardation by the edges of the quadrilateral bionic pits, the results show that compared with the polished surface, the surface morphology of the quadrilateral bionic pits has a significant effect on the growth of fatigue cracks and a better blocking effect;

(3) The analysis results of the fatigue fractures of the quadrilateral and hexagonal bionic pits show that the sources of fatigue cracks all originate from the machined surface. The fractures are brittle fractures in the macroscopic view, and mixed fracture forms of cleavage fracture and dimple fracture in the microscopic view. There is a certain amount of plastic deformation inside the material, which also helps to improve the fatigue crack growth resistance of the bionic surface. 


\begin{abstract}
Author Contributions: Conceptualization, Y.C. and W.Z.; methodology, Y.C. and F.W.; software, Y.C., F.W. and Q.H.; investigation, Y.C. and W.Z.; resources, Y.C.; data curation, Y.C. and F.W.; writing—original draft preparation, Y.C.; writing—review and editing, Y.C.; supervision, W.Z.; project administration, Y.C.; funding acquisition, Y.C. All authors have read and agreed to the published version of the manuscript.
\end{abstract}

Funding: This research was funded by the Research Projects of Basic Scientific Research Business Expenses of Provincial Colleges and Universities in Heilongjiang Province (145109410), the basic scientific research business cost research project of Heilongjiang Provincial Colleges and universities (135409102), Heilongjiang intelligent manufacturing equipment industrialization Collaborative Innovation Center (135409102), and the National Natural Science Foundation of China (51775151).

Institutional Review Board Statement: Not applicable.

Informed Consent Statement: Not applicable.

Data Availability Statement: All data included in this study are available upon request by contact with the corresponding author.

Conflicts of Interest: The authors declare no conflict of interest.

\title{
References
}

1. Liu, X.; Jiang, Y.; Wu, S.; Li, M.; Yue, C.; Chen, T. Research progress of milling process on hardened steel molds used in automobile panels. J. Mech. Eng. 2016, 52, 35-57. [CrossRef]

2. Guillemot, N.; Lartigue, C.; Billardon, R.; Mawussi, B.K. Prediction of the endurance limit taking account of the microgeometry after finishing milling. Int. J. Interact. Des. Manuf. 2010, 4, 239-249. [CrossRef]

3. Huang, W.; Zhang, P.; Yang, T.; Zhao, J.; Su, C. Tool path selection for high-speed ball-end milling process of hardened AISI D2 steel based on fatigue resistance. Int. J. Adv. Manuf. Technol. 2020, 110, 2239-2247. [CrossRef]

4. Suraratchai, M.; Limido, J.; Mabru, C.; Chieragatti, R. Modelling the influence of machined surface roughness on the fatigue life of aluminium alloy. Int. J. Fatigue 2008, 30, 2119-2126. [CrossRef]

5. Yao, C.; Wu, D.; Jin, Q. Influence of high-speed milling parameter on 3D surface topography and fatigue behavior of TB6 titanium alloy. Trans. Nonferr. Met. Soc. China 2013, 23, 650-660. [CrossRef]

6. Kamat, S.; Su, X.; Ballarini, R.; Heuer, A.H. Structural basis for the fracture toughness of the shell of the conch Strombus gigas. Nature 2020, 405, 1036-1040. [CrossRef] [PubMed]

7. Ma, S.; Zhou, T.; Zhou, H.; Chang, G.; Zhi, B.; Wang, S. Bionic repair of thermal fatigue cracks in ductile iron by laser melting with different laser parameters. Metals 2020, 10, 101. [CrossRef]

8. Ma, S.Y.; Zhou, T.; Zhou, H.; Pang, X.Y.; Zhi, B.F.; Chang, G.; Wang, S.Y. Thermal fatigue crack resistance of ductile iron biomimetic crack blocked units fabricated by laser remelting. Lasers Eng. 2020, 46, 225-244.

9. Lu, Y.; Ripplinger, K.; Huang, X.; Mao, Y.; Detwiler, D.; Luo, A.A. A new fatigue life model for thermally-induced cracking in H13 steel dies for die casting. J. Mater. Process. Technol. 2019, 271, 444-454. [CrossRef]

10. Liu, L.; Yu, Y.; Jia, Z.; Chen, Y. Thermal fatigue performance analysis of laser-filled bionic coupling of H13 steel. Trans. China Weld. Inst. 2019, 40, 6-10.

11. Zhang, Z.; Zhou, H.; Ren, L.; Tong, X.; Shan, H.; Liu, L. Effect of units in different sizes on thermal fatigue behavior of 3Cr2W8V die steel with biomimetic non-smooth surface. Int. J. Fatigue 2009, 31, 468-475. [CrossRef]

12. Jia, Z.X.; Li, J.Q.; Liu, L.J.; Zhou, H. Performance enhancements of high-pressure die-casting die processed by biomimetic laser-remelting process. Int. J. Adv. Manuf. Technol. 2012, 58, 421-429. [CrossRef]

13. Cong, D.; Zhou, H.; Ren, Z.; Zhang, Z.; Zhang, H.; Meng, C.; Wang, C. The thermal fatigue resistance of H13 steel repaired by a biomimetic laser remelting process. Mater. Des. 2014, 55, 597-604. [CrossRef]

14. Cong, D.; Zhou, H.; Ren, Z.; Zhang, H.; Ren, L.; Meng, C.; Wang, C. Thermal fatigue resistance of hot work die steel repaired by partial laser surface remelting and alloying process. Opt. Lasers Eng. 2014, 54, 55-61. [CrossRef]

15. Meng, C.; Zhou, H.; Zhang, H.; Tong, X.; Cong, D.; Wang, C.; Ren, L. The comparative study of the thermal fatigue behavior of H13 die steel with biomimetic non-smooth surface processed by laser surface melting and laser cladding. Mater. Des. 2013, 51, 886-893. [CrossRef]

16. Tong, X.; Zhou, H.; Liu, M.; Dai, M.J. Effects of striated laser tracks on thermal fatigue resistance of cast iron samples with biomimetic non-smooth surface. Mater. Des. 2011, 32, 796-802. [CrossRef]

17. Tong, X.; Dai, M.J.; Zhang, Z.H. Thermal fatigue resistance of H13 steel treated by selective laser surface melting and CrNi alloying. Appl. Surf. Sci. 2013, 271, 373-380. [CrossRef]

18. Yin, Y.; Wang, Y.; Xu, Z.-Y.; Yu, W.-J.; Li, R.-T.; Liu, H. Repair and characterization of Cr12MoV dies based on laser cladding by wire. Surf. Technol. 2019, 48, 312-319.

19. Meng, C.; Wu, C.; Wang, X.; Li, J.; Cao, R. Effect of thermal fatigue on microstructure and mechanical properties of H13 tool steel processed by selective laser surface melting. Metals 2019, 9, 773. [CrossRef] 
20. Yang, H.X.; Meng, C.; Song, G.Y.; Ning, T.F. Effect of electropulsing and laser biomimetic coupling techniques on the thermal fatigue behaviour of hot worked die steel. Lasers Eng. 2018, 39, 113-126.

21. Zhi, B.; Zhou, T.; Zhou, H.; Zhang, P.; Ma, S.; Chang, G. Improved localized fatigue wear resistance of large forging tools using a combination of multiple coupled bionic models. SN Appl. Sci. 2019, 1, 1773-1779. [CrossRef]

22. Wenqi, Y.; Min, H.U. Study on wear and thermal fatigue performance about Bionic non-smooth coupling mold. Hot Work. Technol. 2016, 199-205.

23. Wang, M. Principle and Technology of Anti-Fatigue Manufacturing; Jiangsu Science and Technology Press: Nanjing, China, 1999.

24. Paris, P.C.; Erdogan, F. A critical analysis of crack propagation laws. J. Basic Eng. 1963, 85, 528-533. [CrossRef]

25. Liu, H. Study on High Speed Milling of Hardened Steel Surface Quality Based on Service Performance; Harbin University of Science and Technology: Harbin, China, 2016.

26. Wu, C. Simulation Study on Residual Stress of Cr12MoV Surface in Dry Hard Turning; Lanzhou University of Technology: Lanzhou, China, 2017.

27. Cheng, H.; Sun, J.; Li, J.; Ren, L. The body wall surface structure of the stink bug and its relationship with the function of reducing viscosity and desorption. Acta Entomol. 2002, 45, 175-181.

28. Zhao, Z.Y. A new age of materials science and engineering. J. Aeronaut. Mater. 2016, 36, 1-6. 